\title{
Feasibility Project for Shipping CNG from Cyprus to North Adriatic Arc
}

\section{G. Trincas}

Department of Engineering and Architecture, University of Trieste, Trieste, Italy

\begin{abstract}
The rationale of CNG option in prospective regional markets like the Mediterranean is that the offtake and delivery of small-to-medium sized gas fields are less competitive for LNG or subsea pipeline transport modes. The needed integration between logistics and rational ship design has been the main driver to this paper. Hence, the main goal is selection of the optimal fleet configuration for shipping the compressed natural gas from the Aphrodite basin to the Northern Adriatic Arc with various export rates for a given number of gas production years. To this end, a rational scheme has been implemented which integrates a menu of CNG prototype ships into a logistics framework. The final result of this paper is a self-standing feasibility study for the marine transport of CNG across the East Med corridors, complete of cost evaluation, at an accuracy level sufficient to make decision on possible implementation of this transport mode as an economically convenient alternative to subsea pipelines.
\end{abstract}

\section{INTRODUCTION}

Politicians and decision makers are always discussing on how to safeguard the countries' energy supply ahead of potential geopolitical crises. Natural gas has become a primary resource of energy also because it has low environmental impact. So far, natural gas is mostly moved through onshore and offshore pipeline networks, whilst a minor part of the world's gas is shipped by LNG ships. Global gas trading patterns are changing while gas pricing is increasingly based on gas-on-gas fundamentals and is less and less correlated to oil indexes.

A new mode of transport is going to be available in future years, e.g. the marine compressed natural gas $(\mathrm{CNG})$ transport, which will be the unique competitor to pipelines on short and medium haul distances. Marine transport of CNG will allow upstream oil \& gas companies to monetize gas reserves that otherwise would remain stranded. Even though CNG technology is still unproven at least as far as large-sized pressure vessels are concerned, recognition of $\mathrm{CNG}$ advantages could open involvement of many shipping and shipbuilding industry in a new business. Of course, such a business will depend on securing long-term contracts with gas suppliers since CNG ships cannot carry any other commodity.

A regional niche for $\mathrm{CNG}$ and floating $\mathrm{CNG}(\mathrm{FCNG})$ is an affordable solution also for small or stranded reserves to be shipped at distances less than 2,000 nautical miles (nm), where pipeline and LNG shipments are technically impractical or too expensive. LNG onshore facilities are expensive and the dual production process (liquefaction
Regasification) is costly and energy wasteful. According to the LNG Industry magazine a FCNG system typically costs 45\% less than the cost of a FLNG: FCNG 850 \$/tpa versus FLNG 1,500 \$/tap (tons per annum).

Unfortunately, so far inability to develop an affordable marine CNG solution has hindered take-off of CNG mode of transport. Reason for this state-of-art is twofold:

- the pressure vessels designed and sometimes certified for marine transport are inadequate, since they are too heavy and/or have a too small diameter; the result is that the CNG ships designed so far are too large and expensive, and with low cargo density in holds, making the marine $\mathrm{CNG}$ transport still uncompetitive with pipelines even in short-medium haul distances;

- lack of integration between logistics and ship design has not permitted yet to tailor and optimize a CNG fleet for a specific market; many studies are available (Economides and Mokhatab, 2007; Nikolaou et al., 2009), mainly devoted to modelling the logistics for optimal routing and distribution schedules of $\mathrm{CNG}$ ships, but without due identification of the best CNG ships' size and technical features leading to designing optimal fleets (Trincas, 2014).

In the Eastern Mediterranean investors can envisage a lot of CNG export opportunities to Croatian, Greek and Italian markets created by the new reserves off Cyprus and Israel. As a case study this paper summarizes economics of marine CNG shipment from the offshore gas fields in the Southeastern Mediterranean to the Northern Adriatic Arc; in particular from the Aphrodite gas field to the offshore international waters in the Gulf of Trieste. 


\section{SUBSEA PIPELINES}

Pipelines dominate the international gas trade, whilst LNG only accounts for 22 percent of the international trade. However, rebalancing of natural gas markets, via gas pipelines, is often faced with technical, economic and even political limitations:

- the growing distance from the wells and reserves to the larger consumer zones may result in technical and economic impossibilities for long-distance pipelines;

- the diversification of supply sources is also a primary concern of the importing countries; LNG, and $\mathrm{CNG}$ even more, meets this political necessity;

- the rapid development of gas-fired power plants on coastal and nearby sites, relying on very competitive technologies, obviously offers a huge market for LNG and CNG projects;

- the general trend of liberalization of energy markets is causing the breakup of the traditional industrial structures, diversification of contractual forms, and proliferation of players and trading flows; this could favor the growth of independent $\mathrm{LNG}$ and $\mathrm{CNG}$ import terminals.

So far, subsea pipeline technologies have been developed and applied mainly for production of gas resources which are considered stranded. Building a large-diameter pipeline system to link an offshore gas field to long distance receivers requires huge, upfront capital investment. Transporting gas in long offshore pipelines poses many challenges; among the others, stability of pipeline structures over decades in strong currents, shifting seabed and steep seabed slopes. Gas pipeline projects are also characterized by long lead times as it could take up to ten years between the conception of a project and its first revenues, increasing financial risks associated with it.

Pressure, diameter and length are the primary constraint variables in the hydraulic-mechanical design of deep water pipelines. Compression system requirements are significant in terms of capital and operating expenditures. As regards mechanics, these pipelines require proper wall thickness to withstand high external pressures and pressure transitions from deep water to land.

It is almost impossible, however, to find exact costs of gas pipelines because technical parameters as well as natural and climatic conditions are always different. Deep water pipelines in the South-East Mediterranean would be exposed to water depths of up to 2,800 meters. The technology gap for deep water pipelines are challenging, but feasible to be closed. But at which price?

Today, the gas supply cost per kilometer of current subsea pipeline projects in regions with hot and mild climate is estimated to exceed $\$ 4.0$ million per nautical mile. With over 1,300 kilometers of pipeline connecting Cyprus-Israel gas field to the Eastern Mediterranean regions and enabling a throughput of about 15 to 25 billion cubic meters per year, capital expenditure is expected to exceed $\$ 5$ billion.
As can be seen in Table 1, the most important costs are labor costs which increased a lot in one decade, whereas material costs are being reduced; miscellaneous includes surveying, engineering, administration, communications, overheads, equipment, taxes, interests, etc.

Table 1. Offshore pipeline construction costs $(\$ / \mathrm{nm})$ (source: Oil \& Gas Journal, Pipeline Economics Survey).

\begin{tabular}{|l|c|c|}
\hline Cost per Item & $2000-2001$ & $2012-2013$ \\
\hline Material & 414,000 & 252,000 \\
Labor & $1,537,000$ & $3,388,000$ \\
Damages & 117,000 & 138,000 \\
Miscellaneous & 510,000 & 716,000 \\
\hline Total & $2,578,000$ & $4,494,000$ \\
\hline
\end{tabular}

Pipeline operating costs mainly vary according to the number of compressor stations, which require significant amount of fuel and labor costs. Once a pipeline is built, the average cost per unit of throughput will depend basically on the average rate of capacity utilization. A high level of utilization with a high load factor is mandatory to the economic viability of the pipeline.

\section{CNG SHIP DESIGN STRUCTURE}

\subsection{Gas containment system}

The natural gas is carried in pressure vessels (PVs) of Type III (steel liner wrapped with hybrid composite of carbon and glass). Main features of a PV are summarized in Table 2. In these PVs the gas may be compressed to 300 bar at standard temperature and atmosphere and up to 330 bar with mild refrigeration. The internal diameter ranges from 2.0 to 3.0 meters. The lower weight of these pressure vessels with respect to other $\mathrm{CNG}$ technologies and the convenient unit cost per volume of gas transported allow to design CNG ships with a deadweight to displacement ratio almost doubled if compared to designs developed worldwide so far. High variability of PVs' length depends on ship size, capacity and stability-seakeeping constraints.

Table 2. Principal data of pressure vessels

\begin{tabular}{|c|c|c|c|l|c|}
\hline Item & $D_{\text {int }}$ & Length & Pressure & Weight & Cost \\
\hline Value & $2.5 \mathrm{~m}$ & $10-32 \mathrm{~m}$ & $300 \mathrm{bar}$ & $0.85 \mathrm{t} / \mathrm{m}$ & $9,600 \$ / \mathrm{m}$ \\
\hline
\end{tabular}

The pressure vessels are carried within the CNG ship in holds, with rows of eight pressure vessels in each hold. The number (one or two) of longitudinal watertight bulkheads (wtb) depends upon the even (one wtb) or odd number (two wtb) of columns of pressure vessels. The individual holds are isolated separately even during the loading and unloading process where they are filled and emptied hold by hold. For sake of safety precaution in the event of a leakage from pressure vessels, the holds are protected by a double-inerting system to protect against the risk of fire or explosion in the unlikely event of leakage. To this end, the cargo hold spaces surrounding the pressure vessels are filled with nitrogen gas. In the extreme event of a major gas leak, the dome has relief hatches that will open and vent the natural gas. 
Each pressure vessel is fitted with gas leak detection, as required by the class societies (ABS and DNV), in order to allow safe depressurization and insulation in the unlikely event of a gas leak.

\subsection{Menu of ships}

Table 3 summarizes the database of sixteen CNG ships of different capacity ranging from 50 to 900 million of standard cubic feet (mmscf), e.g. within the feasible design capacity space (Trincas, 2014). Designs outside this space identify unfeasible solutions, leading to either waste of ship capacities or insufficient overall capacity of the fleet to satisfy consumption demand. The design capacity space offers a number of feasible solutions. However, as it will be demonstrated later, searching for minimum shipping tariff will lead to fleets with the lower possible number of ships.

The CNG ships have been developed at conceptual design level by means of a multiattribute decisionmaking approach to determine the 'best possible' solution for each assumed gas capacity. To arrive at the final selection of the 'best possible' ships a mathematical design model (MDM) for $\mathrm{CNG}$ ships has been implemented. It is fed by an adaptive Monte Carlo generation module and produces a large set of feasible designs in the attribute space which are then mapped into the design space. Here the feasible designs are filtered by recognition of the Pareto frontier where the nondominated designs are ranked by applying the Čebyšev metric after fuzzification of attributes' outcomes (Trincas, 2002).

The MDM includes a number of technical modules, namely, the topological description of the preliminary general arrangement and capacity plan, preliminary sketch of cargo area structure, electric load analysis, preliminary shipboard handling equipment and piping layout, weight breakdown estimate, speed and power analysis, intact stability and longitudinal strength assessment, deterministic damage stability evaluation in dangerous zones, midship section structure, seakeeping maneuvering - dynamic positioning analysis, vibration analysis etc.. The ship has to be capable of sailing up to and connecting with a STL buoy (loading) and to the SAL system (offloading) without the assistance of tugs. The DP2 Class is preferred, which requires that the failure of any single active component (thrusters, generators, switchboards, etc.) does not cause loss of position.

The MDM performs economic prediction in terms of both capex and opex. The primary attribute is the shipping tariff.

In the generation phase the feasible candidate designs are submitted simultaneously to two crisp constraints, e.g. they have to comply with IMO stability criteria and avoidance of roll resonance and motion coupling in a seaway. As a consequence, the number and length of the pressure vessels for a given gas capacity is determined automatically. Because length of STL room, compressors room, azimuthal thruster space, cofferdams and engine room, height of the twin double bottom and clearance between top of pressure vessels and lower side of the dome, as well as width of double hull and thin-walled longitudinal bulkheads, are almost independent on ship size, the latter is identified at the real beginning of the generation process as a function of expected deadweight and simultaneously constrained by a number of crisp and soft criteria.

The material of ship hull and midship section is of highstrength and low-temperature steel, whereas the material of cargo equipment deckhouse and accommodation is of ordinary structural steel.

The ship is arranged with a centralized electric power generation system, distributing power to the electric propulsion motors, thrusters and cargo equipment and the various ship services. Dual-fuel engines are arranged in a genset mode to supply the required power. The gensets use the natural gas cargo as fuel, along with a percentage (1\%) of marine diesel oil for pilot flame and as reserve whether there is a failure on the gas system. The power demand is inclusive of a $20 \%$ sea margin which represents the average increase in power due to waves and speed. The power module in the MDM determines the continuous service rating (CSR) of the propulsion system for the selected dualfuel engines and generating sets at the optimal service speed; the CSR may range between $85 \%$ and $92 \%$.

Cargo systems include all equipment, piping, valves and control required to fill and discharge the pressure vessels. A single STL loading system supplies the gas to the ship; it is connected to a FPSO (floating production storage and offloading) through a single pipeline. The gas is first compressed on the FPSO from the heel pressure up to 250260 bar. The booster compressor on board is the activated and the pressure vessels are filled to a pressure of 300 bar. Gas is unloaded from the pressure vessels through the SAL system into a subsea pipeline directly to the pipeline network or to a receiving storage facility at an established offloading pressure.

As regards seakeeping analysis, ship's natural periods, vertical motions and accelerations in the foundation of the foremost pressure vessels are assessed using regression equations as derived off-line by application of a fractional factorial design (FFD) technique. The same FFD technique has been applied to derive a simple algorithm to perform a dynamic positioning estimate about the capability of keeping the ship in position under wind speeds up to 50 knots, sea state 5 and current of $1 \mathrm{~m} / \mathrm{s}$.

The gas is priced at an average wellhead cost at the ship loading buoy, inclusive of netback to the gas suppliers as well as pipeline and STL buoy costs. It is assumed that liquid fuels are purchased on the open market. The shipping tariff is calculated based on the net delivered quantity of gas. A heeled gas amount is maintained permanently in each menu of CNG prototype ships into a logistics framework.

The latter selects the number of ships entering in the fleet together with their size and economically optimal service speed, given a number of relevant parameters such as loading and offloading rates per day, distance to the market, connecting and disconnecting time on terminals, 
stand-by time, availability of storage at both origin and destination locations. Final selection of the optimal fleet composition for whichever gas volume to ship is performed on the basis of minimum shipping tariff.

Table 3. Main characteristics of the CNG ships stored in the menu

\begin{tabular}{|c|c|c|c|c|c|c|c|c|c|}
\hline $\begin{array}{l}\text { CNG Capacity } \\
\text { (mmscf) }\end{array}$ & 50 & 100 & 150 & 200 & 250 & 300 & 350 & 400 & 450 \\
\hline Number of PVs & 92 & 140 & 174 & 210 & 217 & 248 & 272 & 306 & 342 \\
\hline PV length (m) & 10.20 & 13.20 & 15.80 & 17.30 & 20.80 & 21.80 & 23.20 & 23.50 & 23.70 \\
\hline Length overall $(\mathrm{m})$ & 155.20 & 166.38 & 171.90 & 175.44 & 180.18 & 180.48 & 185.54 & 185.70 & 186.12 \\
\hline Beam $(m)$ & 22.20 & 25.20 & 27.00 & 28.16 & 31.30 & 32.88 & 34.78 & 35.80 & 37.86 \\
\hline Draft (m) & 4.40 & 5.38 & 5.80 & 6.24 & 6.40 & 6.50 & 6.56 & 6.90 & 7.18 \\
\hline Depth at side $(\mathrm{m})$ & 14.50 & 15.00 & 15.55 & 16.30 & 17.00 & 18.10 & 20.00 & 21.40 & 18.20 \\
\hline Displacement (t) & 9,803 & 13,406 & 16,473 & 19,338 & 23,080 & 25,979 & 28,804 & 31,617 & 34,620 \\
\hline Roll period (s) & 14.90 & 13.81 & 13.74 & 13.76 & 14.16 & 14.29 & 16.24 & 16.70 & 16.76 \\
\hline Total power $(\mathrm{kW})$ & 13,740 & 13,920 & 13,920 & 14,220 & 14,220 & 15,920 & 15,920 & 17,220 & 19,770 \\
\hline Deadweight (t) & 1,100 & 2,042 & 2,978 & 3,919 & 4,856 & 5,787 & 6,742 & 7,657 & 8,615 \\
\hline Ship cost $\left(\$ \cdot 10^{6}\right)$ & 130.20 & 143.40 & 155,30 & 168,00 & 183.60 & 197.90 & 215.60 & 230.30 & 249.70 \\
\hline $\begin{array}{c}\text { CNG Capacity } \\
\text { (mmscf) }\end{array}$ & 500 & 550 & 600 & 650 & 700 & 750 & 800 & 850 & 900 \\
\hline Number of PVs & 310 & 330 & 341 & 352 & 363 & 385 & 418 & 440 & 462 \\
\hline PV length (m) & 28.90 & 29.80 & 31.40 & 33.00 & 34.40 & 34.70 & 34.10 & 34.40 & 34.70 \\
\hline Length overall $(\mathrm{m})$ & 191.28 & 190.08 & 194.28 & 201.52 & 206.26 & 215.84 & 229.90 & 241.92 & 251.4 \\
\hline $\operatorname{Beam}(\mathrm{m})$ & 38.35 & 40.90 & 41.00 & 42.80 & 42.90 & 43.40 & 43.50 & 43.70 & 43.80 \\
\hline Draft (m) & 7.30 & 7.42 & 7.62 & 7.66 & 7.70 & 7.74 & 7.80 & 7.88 & 7.92 \\
\hline Depth at side (m) & 22.90 & 23.80 & 25.40 & 27.00 & 28.40 & 28.70 & 28.10 & 28.40 & 28.70 \\
\hline Displacement $(\mathrm{t})$ & 37,224 & 39,951 & 43,098 & 47,059 & 48,796 & 52,771 & 56,990 & 60,798 & 64,843 \\
\hline Roll period (s) & 15.92 & 15.47 & 17.15 & 16.56 & 18.87 & 18.45 & 17.52 & 17.77 & 18.13 \\
\hline Total power $(\mathrm{kW})$ & 20,540 & 20,610 & 20,610 & 22,830 & 27,420 & 27,480 & 29,700 & 29,700 & 31,200 \\
\hline Deadweight (t) & 9,580 & 10,500 & 11,429 & 12,388 & 13,316 & 14,231 & 15,177 & 16,095 & 17,048 \\
\hline Ship cost $\left(\$ \cdot 10^{6}\right)$ & 234.43 & 242.28 & 250.21 & 266.45 & 273.40 & 285.55 & 301.84 & 310.77 & 323.39 \\
\hline
\end{tabular}

\section{FLEET COMPOSITION}

To select the optimal fleet configuration a rational scheme has been implemented which integrates a menu of $\mathrm{CNG}$ prototype ships into a logistics framework.

The proprietary code selects the number of ships entering in the fleet together with their size and optimal service speed. A number of parameters and constraints are primary drivers of simulation: loading and offloading rates per day, distance to the market, connecting and disconnecting time on terminals, stand-by time. Final selection of the optimal fleet composition is performed on the basis of minimum shipping tariff.

The optimal fleet composition has to guarantee a continuous delivery to the destination terminal, being flaring and re-injection not allowed. The best fleet composition is selected by ranking for the minimum tariff required by the oil \& gas company on an annual basis to transport a volume unit of compressed natural gas.

If the logistics of the $\mathrm{CNG}$ transport mode does not require any storage facility, one can speak of hub-andspoke pattern with continuous-continuous service (CC), where continuous supply and delivery of gas would imply overlap of ships unless flow, size and service speed of ships are optimized. Because of restriction in space, only this service is considered where the loading, offloading and utilization rates are as follows

$Q_{\text {on }}=Q_{\text {off }}=Q_{u}$

To avoid whichever outage or temporal overlapping during the operating cycle (e.g., a round-trip from the delivery site to the source for reloading and return to resume delivery), there has to be a continuous gas supply (ship after ship) at the delivery site to cover consumption demand during the time other CNG ships are on a roundtrip while simultaneously ensuring that the gas source can supply the required natural gas.

This reasoning leads to the general equilibrium equation between the time $T_{n}$ taken by a CNG ship in the fleet to complete a gas distribution cycle and the time $T_{\text {off }}$ spent by the other ships to offload the gas to utilization

$T_{n}=(n-1) T_{\text {off }}$

where $n$ is the number of ships composing the fleet.

The total cycle time is calculated as

$T_{n}=\frac{G_{n}}{Q_{o n}}+\frac{G_{n}}{Q_{o f f}}+T_{r t}$

In equation (2) $G_{n}$ denotes the minimum ship capacity, whilst $T_{r t}=4 t_{c}+L / V$ is the total round-trip time, sum of the time from delivery site to the source and back after 
gas loading plus the total time for disconnecting/ connecting the ship from/to the buoys.

Combination of equations (1) and (2) leads to

$T_{r t}+\frac{G_{n}}{Q_{o n}}=(n-1) \frac{G_{n}}{Q_{o f f}}$

The minimum capacity required to any sister ship composing the fleet can be derived from equation (3) as

$G_{n}=T_{r t}\left[\frac{Q_{o n} \cdot Q_{o f f}}{(n-1) Q_{o n}-Q_{o f f}}\right]$

\section{SHIPPING MODELLING}

Shipping tariffs are determined under a given financial scenario by means of a discounted cash flow model based on key elements which determine the investment's outcomes. These elements include the acquisition cost of the ships, operating costs, tax and interest rates, leverage scheme, economic life, salvage value, etc. Discounted cash flows are calculated on an after tax basis.

Resulting tariffs should be read in relative terms, since the building cost of each ship is evaluated on the basis of average hourly cost from Italian shipyards, whilst daily operating costs are derived from average data for LNG ships and wellhead gas costs from present market information.

The following are key considerations in assessing tariffs:

- Capex (capital expenses for ship building):

- ship capex is spread over three years prior to first gas delivery;

- shipyard overheads assumed as $30 \%$ of overall labor costs;

- expected net profit for shipyard assumed at $6.5 \%$ after taxes;

- included are costs for design, survey, insurance, administration, etc.

- Opex (operating expenses over ship lifetime):

- ship opex is escalated at $2 \%$ per annum starting from first gas delivery;

- MDO cost estimated at $565 \$ / t$;

- natural gas cost estimated at wellhead price $3.15 \$ / \mathrm{mscf}$;

- linear depreciation assumed; scrap value is 25 percent of ship acquisition cost after 20 years;

- 5-year dry-docking and annual M\&R repair costs are included in annual operating expenditures.

- Tax Rate: net present value assessed with corporate tax rate of $10 \%$.

- IRR (internal rate of return) for the ship owner assumed $12.5 \%$ as project return.

The implemented model has been run to analyze the viability of the marine $\mathrm{CNG}$ transport from an offshore loading terminal to an offshore unloading terminal with a source-destination distance of $1350 \mathrm{~nm}$ where the maximum production rate is fixed in $11.25 \mathrm{mmscm} / \mathrm{d}$.

The loading point is identified offshore near, say, an FPSO which may be deemed as the cargo storage facility when the loading rate onboard the CNG ship is higher than the daily gas supply from the wells. During loading operation the CNG ship is connected to the STL buoy which receives the gas compressed at 300 bar from the FPSO via a short subsea pipeline. The offloading point receives gas from a buoy which connects a SALS system installed on board with an onshore treatment plant.

In determining fleet composition, e.g. number of ships, ship size and optimal speed, the following parameters are set:

- ship service speed: range from 15 to 22 knots, with sea margin as $20 \%$ to allow for added resistance in wind and waves;

- connect/disconnect time: 1.5 hours per operation;

- stand by-time: what is needed to round up each oneway voyage to the nearest whole day;

- 355 operating days per year.

\section{SIMULATIONS}

\subsection{Development of Aphrodite gas field}

The Aphrodite gas field is an offshore basin off the southern cost of Cyprus located at the drilling block 12 in the Cyprus' maritime Exclusive Economic Zone (EEZ).

The uncertainties and complexity of the LNG market and excess supply which weighed down on LNG prices, especially in the rich Japanese and Southeastern Asian market, are compelling operators in the Leviathan and Aphrodite gas fields to diversify their planned exports towards Mediterranean markets. Apart from signed deals with the Palestine Power Generation Company, the two Jordanian firms Arab Potash and Jordan Bromine, the Spanish firm Union Fenosa and British Gas, the market could be widened and diversified to include more distant regional markets in South Europe, whilst at the same time spreading and minimizing the risk in a geopolitically troubled area. Some of these markets do not have a large enough demand profile to sustain the commercial viability of onshore regasification terminals or to justify the huge investment for the construction of subsea pipelines. In addition, many clients in South Europe urgently need to replace the highly priced and highly polluting fuel oil, coal, gas oil and diesel plants with natural gas in the generation of electricity.

Huge investments (7-8 billion dollars) and 7-10 years are required for building a subsea pipeline and an LNG export terminal in Cyprus. Therefore, the crucial question for Cyprus is whether it should wait for such a long time before it is able to monetize its gas reserves or whether, alternatively, it can find short-term solutions which will allow it to develop its mineral wealth much faster.

According to the US Geological Survey, the total natural gas reserves inside exclusive economic zones (EEZs) of Israel, Egypt and Lebanon are estimated to be about $14 \mathrm{tcm}$ (tera cubic meters) of which approximately $3 \mathrm{tcm}$ have already been discovered. Therefore, allowing for $3.5 \mathrm{tcm}$ required to meet the domestic demand in Egypt, Israel, Jordan, Lebanon and Palestine for the next thirty years, one can easily deduce that the balance of $10.5 \mathrm{tcm}$ can cater for 
Europe's needs in natural gas for a period of thirty-five years.

While Israel and Cyprus have launched a new push for EU funds to build a pipeline that could bring about $10 \mathrm{bcm}$ of their natural gas to Europe annually, and ease the continent's energy security problems, the pipeline solution would be very risky without a complete resolution of political conflicts and instability in the region. If built, a pipeline connecting the Cyprus-centered project to Northern Mediterranean regions through an Eastern Mediterranean corridor would be the longest in the world, passing through depths of up to $3,000 \mathrm{~m}$.

Given that some of these offshore gas fields are stranded and smaller than 5 tcf, their monetization could be implemented by means of $\mathrm{CNG}$ projects in order to maximize the returns over the smallest period of time possible. Until additional, presently unexplored reserves in the Cyprus EEZ are explored to provide additional natural gas to justify the construction of an LNG liquefaction plant for shipping gas to the Far East, the Exploration \& Production activities may be served by FPSO and CNG SHIP with an estimated time of completion within three years from final investment decision.

$\mathrm{CNG}$ is probably the best option for exporting natural gas from Cyprus to Southern Europe in terms of both initial constant future benefits, whilst a deep water pipeline would be too expensive and LNG would only be costeffective if exported to higher priced Asian markets.

To evaluate influence of different gas volumes loaded at the hub the cases summarized in Table 4 are investigated.

Table 4. Hub-and-spoke simulations

\begin{tabular}{|c|c|c|}
\hline Service & Origin & Destination \\
\hline CC2 & Load at $200 \mathrm{mmscf} / \mathrm{d}$ & Unload at $200 \mathrm{mmscf} / \mathrm{d}$ \\
\hline CC3 & Load at $300 \mathrm{mmscf} / \mathrm{d}$ & Unload at $300 \mathrm{mmscf} / \mathrm{d}$ \\
\hline CC4 & Load at $400 \mathrm{mmscf} / \mathrm{d}$ & Unload at $400 \mathrm{mmscf} / \mathrm{d}$ \\
\hline
\end{tabular}

It is assumed that about 2, 3 and $4 \mathrm{bcm}$ per annum $(\mathrm{bcm} / \mathrm{a})$ are required to meet the regional demand in the Northern Adriatic regions for the next 20 years.

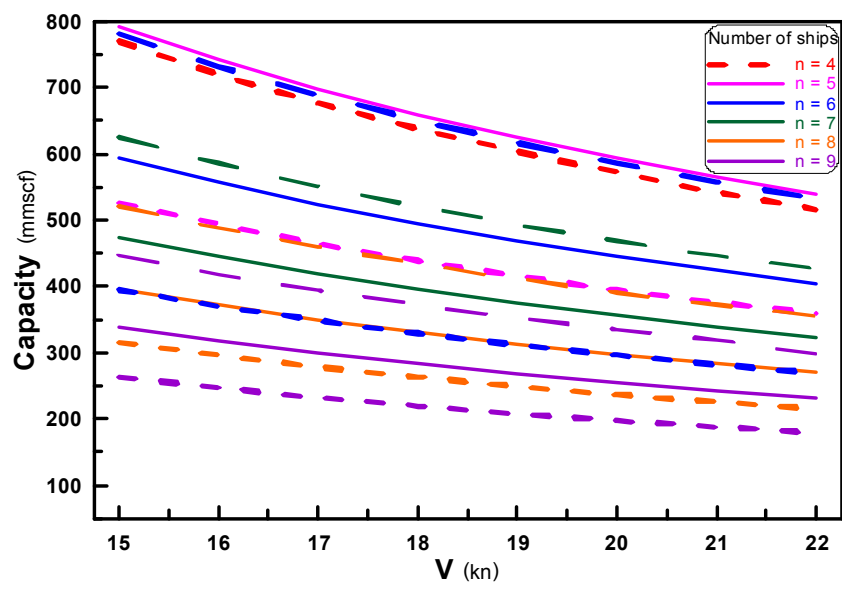

Figure 1 . Ship capacity vs. ship speed for feasible fleets

Figure 1 summarizes the results of simulation for the fleet composition in absence of storage facilities at three different loading/unloading rates. The capacity of each ship in fleets made up of different number of ships is given as a decreasing function of ship service speed. As expected, ship size diminishes when the number of ships in a fleet increases.

Styles of the lines are to be read as follows: short dashed lines for $\mathrm{CC} 2$, solid lines for $\mathrm{CC} 3$ and long dashed lines for CC4. Number of ships refers to the number of ships composing a feasible fleet as a function of shipped volume of gas and distance from origin to destination market.

The effect of speed on ship capacity, e.g. size, is much more pronounced for medium-size and large CNG ships. Also the amount of gas to be shipped affects the actual capacity of a ship much more in a fleet consisting of few ships of larger capacity.

For each simulation stated in Table 4 unlevered and levered investments for the fleet are considered.

\subsection{Unlevered investment capital}

The capacity of each ship in fleets, which are made up of different number of ships, is given as a function of ship service speed. As expected, ship size diminishes when the number of ships in a fleet increases. The effect of speed on ship capacity (size) is much more pronounced for large CNG ships. Also the amount of gas to be shipped affects the actual capacity of a ship much more in a fleet consisting of few ships of larger capacity.

The lines depicted in Figure 2 show that for the continuous service the shipping tariff increases dramatically when the number of ships increases with corresponding decrease of ship size. Each point in a group (fleet) denotes a ship with a specific service speed ( $\mathrm{V}=15$, $16,17,18,19,20,21,22 \mathrm{kn})$. For the considered logistics parameters, the best fleet is composed by four ships when $5.65 \mathrm{mmscf} / \mathrm{d}$ are shipped, whilst the best fleet is composed by five larger ships with lower tariff when both loading and offloading rates are $8.50 \mathrm{mmscm} / \mathrm{d}$.

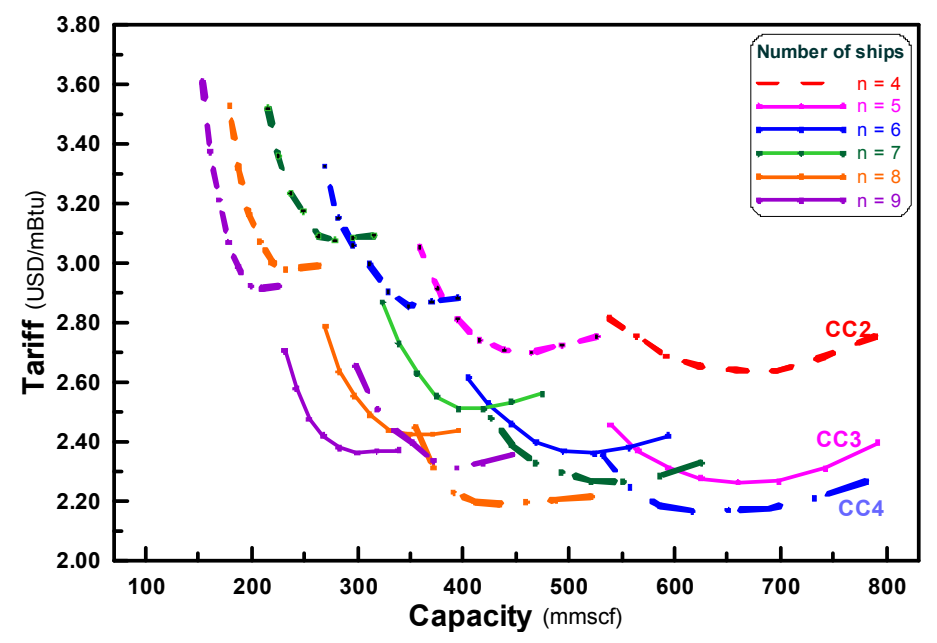

Figure 2. Shipping tariff vs. ship capacity

Figure 3 shows the optimal service speed for the feasible fleets which is singled out by the lower shipping tariff. These speeds are about 17 and 18 knots for the fleets of four and five ships, respectively. It is worth noticing that the optimal speed generally diminishes when a fleet consists of a larger number of ships. 


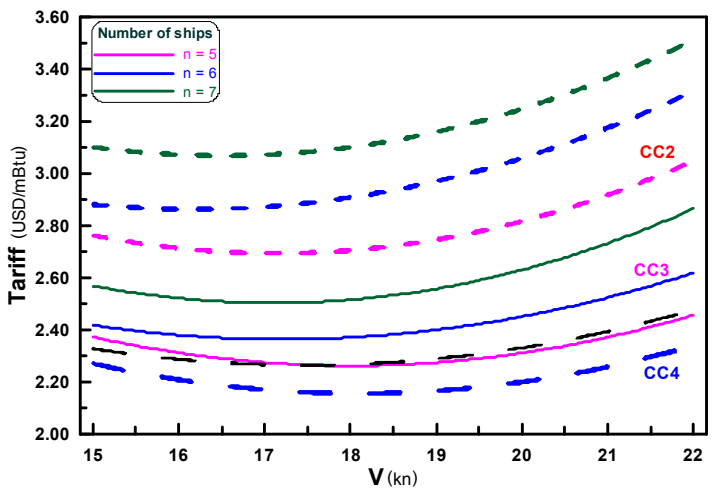

Figure 3. Shipping tariff vs. ship speed

\subsection{Levered investment capital}

In the case of leverage the following assumptions have been considered:

- borrowing, 60 percent;

- interest rate, 5.5 percent;

- loan payback period, 8 years (principal and interest).

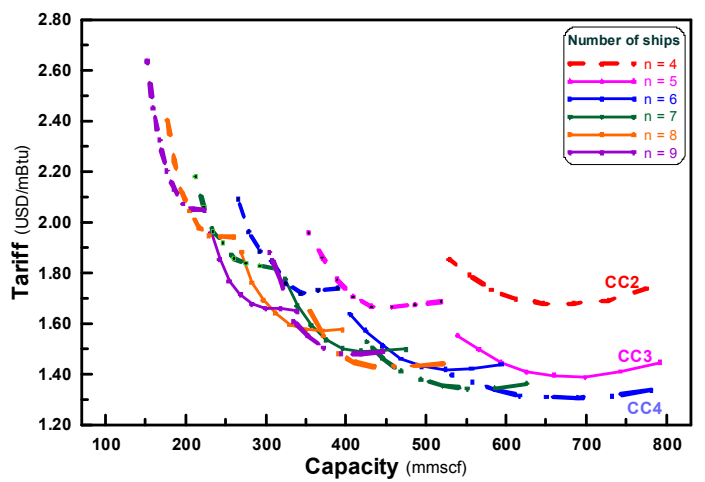

Figure 4. Shipping tariff vs. ship capacity

If one looks at Figures 4 and 5 and compares the distributions of the shipping tariff to the corresponding ones in the case of unlevered capital, it is evident that the major effect of the leverage in capex is the dramatic reduction of that economic parameter.

In addition, in the $\mathrm{CC} 2$ case the number of ships for the optimal fleet is no more four but five ships of much lower size. As regards the $\mathrm{CC} 3$ and $\mathrm{CC} 4$ cases, the number of ships for the optimal fleets remain the same even though the ships have a bit larger capacity with economically lower speeds, moving from $18-19 \mathrm{kn}$ to $17 \mathrm{kn}$.

These results confirm that even in the simplest CC service, no integrated consideration of logistics and conceptual designing of ships can lead to wrong decision making.

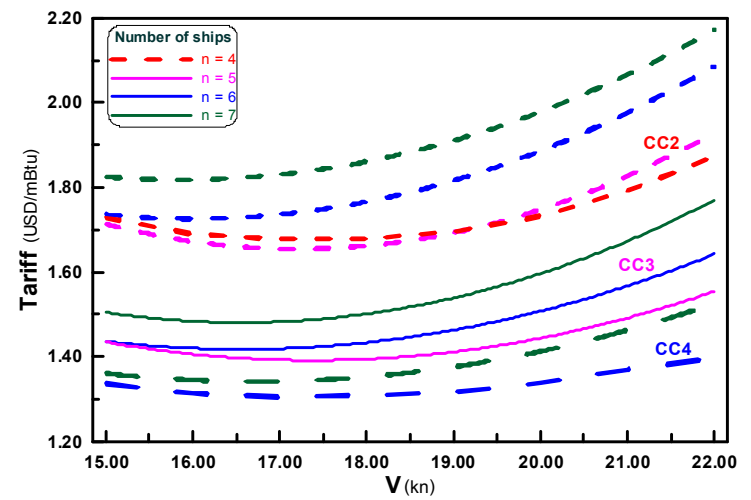

Figure 5. Shipping tariff vs. ship speed

\subsection{Summary}

Finally, summary of technical-economic evaluations for the selected transport scenarios is offered in Table 5. It is clear that larger availability of stranded gas reduces initial investment and tariff (compare CC4 with $\mathrm{CC} 3$ and $\mathrm{CC} 2$ ).

Figures 6 make it easy to see how much the demanded volume of gas affects the shipping tariff. For distant regional markets, such as the Cyprus - Northern Adriatic haul, it appears that there is probably a minimum volume of gas to ship which makes the CNG marine business highly convenient: moving from $2 \mathrm{bcm} / \mathrm{a}$ to $3 \mathrm{bcm} / \mathrm{a}$ the decrease in shipping tariff is much higher than moving from $\mathrm{CC} 3$ to $\mathrm{CC} 4$ service case.

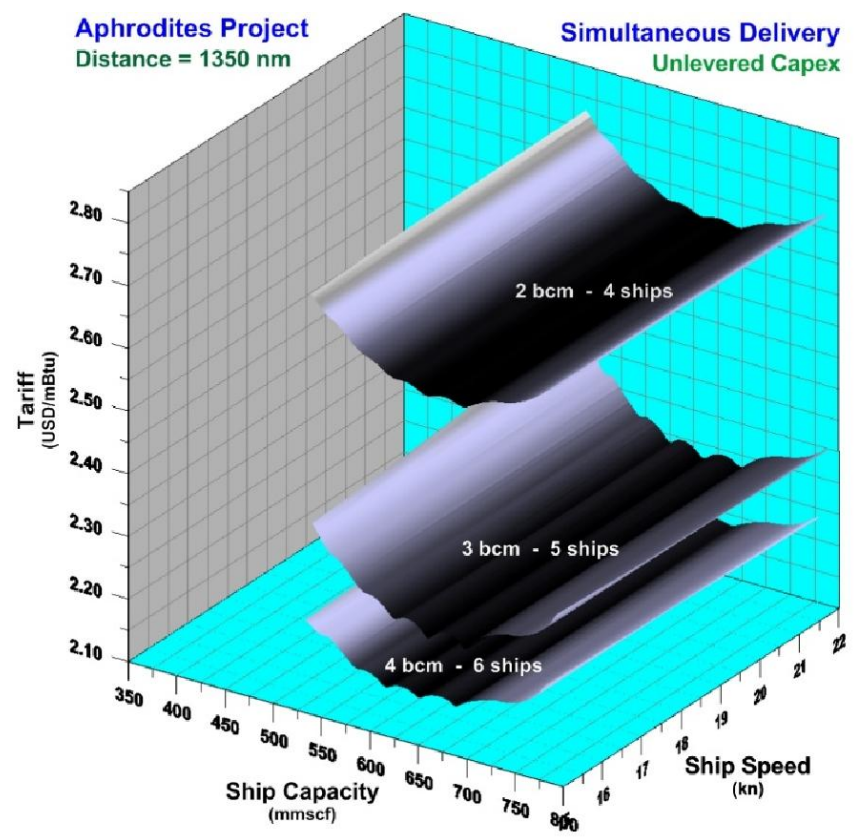

Figure 6a. Tariff vs. ship capacity and ship speed for unlevered investment capital

Table 5. Main data for the best fleets in different scenarios

\begin{tabular}{|c|c|c|c|c|c|c|c|c|}
\hline $\begin{array}{c}\text { Service } \\
\text { Case }\end{array}$ & $\begin{array}{c}\text { Fleet } \\
\text { Financing }\end{array}$ & $\begin{array}{c}\text { No. of } \\
\text { Ships in } \\
\text { the Fleet }\end{array}$ & $\begin{array}{c}\text { Capacity } \\
\text { per Ship } \\
\text { (mmscf) }\end{array}$ & $\begin{array}{c}\text { No. of } \\
\text { Pressure } \\
\text { Vessels }\end{array}$ & $\begin{array}{c}\text { Length of } \\
\text { Pressure } \\
\text { Vessels }(\mathrm{m})\end{array}$ & $\begin{array}{c}\text { Service } \\
\text { Speed } \\
(\mathrm{kn})\end{array}$ & $\begin{array}{c}\text { Capex } \\
\text { per Fleet } \\
\left(\$ \cdot 10^{6}\right)\end{array}$ & $\begin{array}{c}\text { Shipping } \\
\text { Tariff } \\
(\$ \mathrm{mBtu})\end{array}$ \\
\hline \multirow{2}{*}{$\mathrm{CC} 2$} & unlevered & 4 & 696 & 362 & 34.40 & 17 & 1,085 & 2.636 \\
& levered & 5 & 458 & 293 & 28.00 & 17 & 1,122 & 1.665 \\
\hline \multirow{2}{*}{$\mathrm{CC} 3$} & unlevered & 5 & 660 & 354 & 33.20 & 18 & 1,345 & 2.262 \\
& levered & 5 & 698 & 362 & 34.40 & 17 & 1,260 & 1.387 \\
\hline \multirow{2}{*}{$\mathrm{CC} 4$} & unlevered & 6 & 616 & 345 & 31.90 & 19 & 1,530 & 2.166 \\
& levered & 6 & 689 & 360 & 34.30 & 17 & 1,625 & 1.305 \\
\hline
\end{tabular}




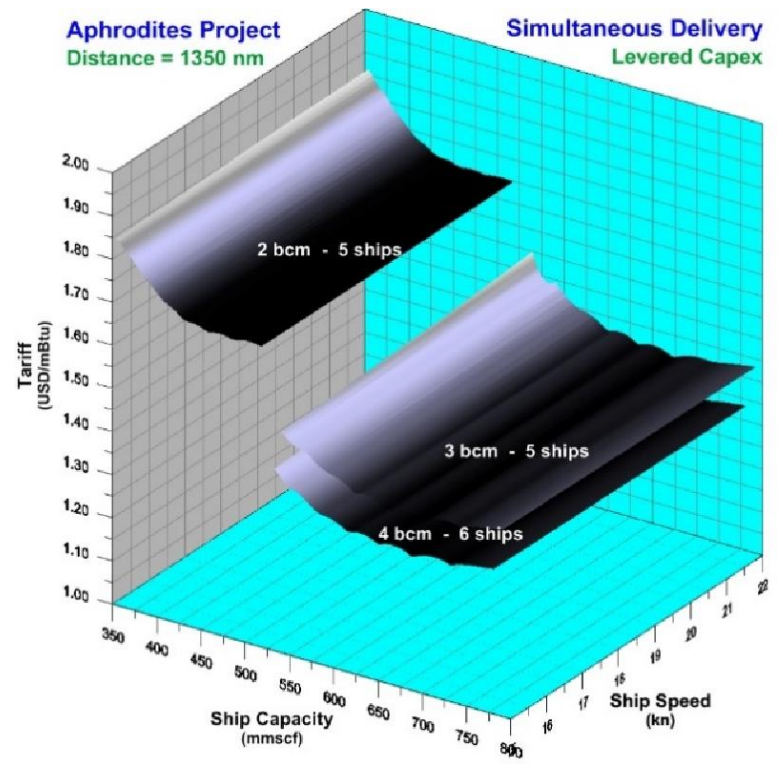

Figure 6 b. Tariff versus ship capacity and ship speed for levered investment capital

\section{CNG VERSUS PIPELINE}

Table 6 shows the value chain of CNG business, where the all-in cost ranges from 2.30 to $4.70 \$ / \mathrm{mBtu}$. The greatest variability is in upstream feedstock for shipping.

Table 6. CNG value chain $(\$ / \mathrm{mBtu})$

\begin{tabular}{|c|c|c|c|c|}
\hline E\&P & Loading & Shipping & Offloading & Total \\
\hline $0.5-1.0$ & $0.1-0.2$ & $1.5-3.0$ & $0.2-0.3$ & $2.7-4.7$ \\
\hline
\end{tabular}

Table 7 compares the netbacks to operators generated by $\mathrm{CNG}$ and pipeline technologies assuming that about 2 billion cubic meters per annum are delivered with no leverage for the investment capital. Price of gas, cost components and netback are measured in US dollars per million British thermal units. Public information has been utilized together with some assumption: 2014 European average natural gas price; pipeline capex of $4 \$ / \mathrm{nm}$ with no opex included; gas consumed as fuel valued as shrinkage.

Table 7. Exports from Aphrodite basin to North Adriatic

\begin{tabular}{|l|c|c|}
\hline Technology & CNG & Pipeline \\
\hline Shipping Distance & \multicolumn{2}{|c|}{$1,350 \mathrm{~nm}$} \\
\hline Load Location & \multicolumn{2}{|c|}{ Cyprus gas blocks } \\
\hline Unload Destination & \multicolumn{2}{|c|}{ Gulf of Trieste } \\
\hline Market Price of Gas & 10.00 & 10.00 \\
\hline Load Compression & 0.80 & - \\
\hline $\begin{array}{l}\text { Floating Production, } \\
\text { Storage, Offloading }\end{array}$ & 2.85 & 2.50 \\
\hline Transportation Tariff & 2.65 & 5.80 \\
\hline Netback & 3.70 & 1.70 \\
\hline
\end{tabular}

Some considerations may be derived. Given the natural gas price in Europe and the corresponding transportation costs, for the East Mediterranean's natural gas the CNG mode of transportation yields a higher netback than the one generated by pipeline in the considered regional market. However, it must be emphasized that for the gas producers the higher netbacks of FCNG are accompanied by the fact that the capex as well as the implementation risks are undertaken by the shippers of the CNG ships.

\section{CONCLUSIONS}

Marine CNG technology is becoming a simple, safe and reliable option for marine transportation of moderate gas volumes within $2,500 \mathrm{~km}$. It will fill the gap between pipelines and LNG for smaller and distant gas fields. Use of Type III large pressure vessels may reduce the cost of CNG shipping, offering transport tariffs much lower than subsea pipelines.

In addition, CNG technology allows monetization of offshore and stranded gas reserves faster and at a much lower capex than LNG and pipeline. It can be implemented as a temporary solution for large gas reserves before implementation of a pipeline or LNG transportation at a later stage of development.

By simulating the marine $\mathrm{CNG}$ transport from the Aphrodite gas field to the Northern Adriatic Arc this paper has demonstrated that marine CNG transport has many technical and cost advantages over pipelines, thus overturning the economics of development of small offshore fields by making their exploitation commercially viable whilst providing a cost effective and reliable means to ship natural gas with low capital charges.

In their evaluation of the long-term commercial viability of a project, gas producers take a global view of the markets as there are critical cost drivers impacting their netbacks, such as market prices and transportation costs. Numerous LNG and pipeline projects have boost supply to exceed demand leading to a revaluation of these high-cost projects some of which have been already abandoned. All these considered, comparative advantage of marine CNG technology lies in the small project footprint as well as in lower capex and opex, hence competitive transportation tariffs, in the regional shipment markets.

\section{REFERENCES}

Economides, M., Mokhatab, S.: Compressed Natural Gas: Monetizing Stranded Gas, 2007.

Nikolaou, M.: Optimizing the Logistics of Compressed Natural Gas Transportation by Marine Vessels, Journal of Natural Gas and Engineering, Vol. 2, 2010, pp. 1-20.

Nikolaou, M., Economides, M., Wang, X., Marongiu-Porcu, M.: Distributed Compressed Gas Sea Transport, Proc. 2009 Offshore Technology Conference, Houston, OTC 19738, 2009, pp. 1-14.

Sevkli, M.: An Application of the Fuzzy Electre Method for Supplier Selection, Int. Journal of Production Research, 2009, Vol. 48, no. 12, pp. 3393-3405.

Trincas, G.: Survey of Design Methods and Illustration of Multiattribute Decision Making System for Concept Ship Design, Proc. Third Int. Conference on Marine Industry, MARIND'2001, Varna, 2001, Vol. III, pp. 21-50.

Trincas, G.: Optimal Fleet Composition for Marine Transport of Compressed Natural Gas from Stranded Fields, Proc. $2^{\text {nd }}$ INT_NAM Conference, INT-NAM 2014, Alkan A.D. Ed., Istanbul, pp. 25-38. 